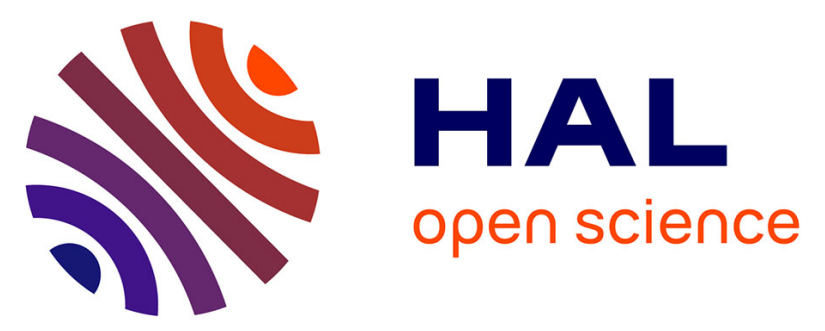

\title{
Disparities in quality of care for colon cancer between hospitals in the Netherlands
}

\author{
M.A.G. Elferink, M.W.J.M. Wouters, P. Krijnen, V.E.P.P. Lemmens, \\ M.L.E.A. Jansen-Landheer, C.J.H. van de Velde, S. Siesling, R.A.E.M. \\ Tollenaar
}

\section{To cite this version:}

M.A.G. Elferink, M.W.J.M. Wouters, P. Krijnen, V.E.P.P. Lemmens, M.L.E.A. Jansen-Landheer, et al.. Disparities in quality of care for colon cancer between hospitals in the Netherlands. EJSO European Journal of Surgical Oncology, 2010, 36, 10.1016/j.ejso.2010.05.026 hal-00612399

\section{HAL Id: hal-00612399 https://hal.science/hal-00612399}

Submitted on 29 Jul 2011

HAL is a multi-disciplinary open access archive for the deposit and dissemination of scientific research documents, whether they are published or not. The documents may come from teaching and research institutions in France or abroad, or from public or private research centers.
L'archive ouverte pluridisciplinaire HAL, est destinée au dépôt et à la diffusion de documents scientifiques de niveau recherche, publiés ou non, émanant des établissements d'enseignement et de recherche français ou étrangers, des laboratoires publics ou privés. 


\section{Accepted Manuscript}

Title: Disparities in quality of care for colon cancer between hospitals in the Netherlands

Authors: M.A.G. Elferink, M.W.J.M. Wouters, P. Krijnen, V.E.P.P. Lemmens, M.L.E.A. Jansen-Landheer, C.J.H. van de Velde, S. Siesling, R.A.E.M. Tollenaar

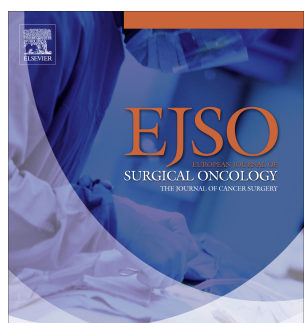

PII: S0748-7983(10)00155-1

DOI: $\quad$ 10.1016/j.ejso.2010.05.026

Reference: $\quad$ YEJSO 2988

To appear in: European Journal of Surgical Oncology

Received Date: 19 May 2010

Accepted Date: 27 May 2010

Please cite this article as: Elferink MAG, Wouters MWJM, Krijnen P, Lemmens VEPP, Jansen-Landheer MLEA, van de Velde CJH, Siesling S, Tollenaar RAEM. Disparities in quality of care for colon cancer between hospitals in the Netherlands, European Journal of Surgical Oncology (2010), doi: 10.1016/ j.ejso.2010.05.026

This is a PDF file of an unedited manuscript that has been accepted for publication. As a service to our customers we are providing this early version of the manuscript. The manuscript will undergo copyediting, typesetting, and review of the resulting proof before it is published in its final form. Please note that during the production process errors may be discovered which could affect the content, and all legal disclaimers that apply to the journal pertain. 
Disparities in quality of care for colon cancer between hospitals in the Netherlands

M.A.G. Elferink ${ }^{1}$, M.W.J.M. Wouters ${ }^{2,3}$, P. Krijnen ${ }^{4}$, V.E.P.P. Lemmens ${ }^{5,6}$, M.L.E.A. Jansen-Landheer ${ }^{7}$, C.J.H. van de Velde ${ }^{2}$, S. Siesling ${ }^{1,8}$, R.A.E.M. Tollenaar ${ }^{2}$

Study performed by the working party 'Quality of cancer care' of the Signalling Committee Cancer of the Dutch Cancer Society

${ }^{1}$ Department of Research, Comprehensive Cancer Centre North East, P.O. Box 330, 9700 AH Groningen, The Netherlands; m.elferink@ikno.nl, s.siesling@ikno.nl

${ }^{2}$ Department of Surgery, Leiden University Medical Centre, P.O. Box 9600, 2300 RC Leiden, The Netherlands; m.j.w.m.wouters@lumc.nl, c.j.h.van_de_velde@lumc.nl, r.a.e.m.tollenaar@lumc.nl

${ }^{3}$ Department of Surgery, Netherlands Cancer Institute, Antoni van Leeuwenhoek Hospital, P.O. Box 90203, 1006 BE Amsterdam, The Netherlands

${ }^{4}$ Leiden Cancer Registry, Comprehensive Cancer Centre West, Schuttersveld 4, 2316 ZA Leiden, The Netherlands; p.krijnen@ikw.nl

${ }^{5}$ Department of Research, Comprehensive Cancer Centre South, P.O. Box 231, 5600 AE Eindhoven, The Netherlands; v.lemmens@ikz.nl

${ }^{6}$ Department of Public Health, Erasmus MC University, P.O. Box 2040, 3000 CA Rotterdam, The Netherlands

${ }^{7}$ Comprehensive Cancer Centre Amsterdam, P.O. Box 9236, 1006 AE Amsterdam, The Netherlands; m.jansen@ikca.nl

${ }^{8}$ Department of Health Technology \& Services Research, University of Twente, P.O. Box 217, 7500 AE Enschede, The Netherlands

Address of correspondence:

M. Elferink

Comprehensive Cancer Centre North East

P.O. Box 330

9700 AH Groningen

E-mail: m.elferink@ikno.nl

Tel: $+31(0) 882345500$

Fax: +31 (0) 882345599 
Abstract

Background.

Aim of this study was to describe treatment patterns and outcome according to region, and according to hospital types and volumes among patients with colon cancer in the Netherlands.

Methods.

All patients with invasive colon carcinoma diagnosed in the period 2001-2006 were selected from the Netherlands Cancer Registry. Logistic regression analyses were performed to examine the influence of relevant factors on the odds of having adequate lymph node evaluation, receiving adjuvant chemotherapy and postoperative mortality. Relative survival analysis was used to estimate relative excess risk of dying according to hospital type and volume.

Results.

In total, 39907 patients were selected. Patients diagnosed in a university hospital had a higher odds (OR 2.47; 95\% $\mathrm{Cl} 2.19-2.78$ ) and patients diagnosed in a hospital with $>100$ colon carcinoma diagnoses annually had a lower odds (OR $0.70 ; 95 \% \mathrm{Cl} 0.64-0.77$ ) of having $\geq 10$ lymph nodes evaluated. The odds of receiving adjuvant chemotherapy was lower in patients diagnosed in teaching hospitals (OR 0.85; 95\% $\mathrm{Cl} 0.73-0.98$ ) and university hospitals (OR $0.56 ; 95 \% \mathrm{Cl} 0.45-0.70$ ) compared to patients diagnosed in non-teaching hospitals. Funnel plots showed large variation in these two outcome measures between individual hospitals. No differences in postoperative mortality were found between hospital types or volumes. Patients diagnosed in university hospitals and patients diagnosed in hospitals with $>50$ diagnoses of colon carcinoma per year had a better survival.

Conclusions.

Variation in treatment and outcome of patients with colon cancer in the Netherlands was revealed, with differences between hospital types and volumes. However, variation seemed mainly based on the level of the individual hospital.

Keywords: colon cancer, staging, treatment, survival, guidelines 
Introduction

Ever since the Institute of Medicine reviewed variations in the quality of cancer care in their 1999 report[1], there is an ongoing debate on this issue, not only in the United States, but also in European countries. Especially, the differences in surgical outcome of patients treated in high and low volume hospitals and between specialized and non-specialized providers, have been studied extensively.[2-4] Most of these studies focus on adverse outcomes like complications and postoperative mortality; few describe differences in the proportion of patients getting optimal treatment for their cancer.

In the Netherlands, colon cancer is one of the most frequent cancers with more than 7500 new diagnoses in 2007.[5] It is also one of the most frequent causes of cancer death with more than 3800 deaths in 2007.[6] According to the current Dutch guideline, the primary treatment for colon cancer is surgery, while adjuvant chemotherapy should be considered for patients with lymph node metastasis. Therefore, adequate lymph node evaluation is important in patients with colon cancer;[7-9] 10 or more lymph nodes should be evaluated for accepting N0 status.[10] However, regional population-based studies in the Netherlands showed large variation on the level of lymph nodes evaluated by pathologists and in the proportion of patients receiving adjuvant chemotherapy.[11;12]

Currently, colon cancer patients are treated in every hospital in the Netherlands. These patients are treated in different settings: university, teaching and non-teaching hospitals; high- and low-volume hospitals, situated in urbanized or more rural regions. It is unknown, to what extent these structural differences between hospitals lead to differences in patterns of care and outcome. A number of studies demonstrated better patient outcomes in teaching versus nonteaching hospitals.[13-15] Others found lower mortality with increasing hospital or surgeon volume.[16;17] However, studies on mortality among patients with colon cancer showed conflicting results: some demonstrated an association between mortality and hospital volume or teaching status, while others did not.[18-24]

Aim of this study was to describe variation in staging, treatment patterns and outcome according to region and, according to type and volume of individual hospitals among patients with colon cancer in the Netherlands. 
Methods

Netherlands Cancer Registry

In the Netherlands, all newly diagnosed malignancies are registered in the nationwide population-based Netherlands Cancer Registry (NCR). The automated pathological archive (PALGA) and the Haematology Departments are the main sources of notification. The National Registry of Hospital Discharge Diagnosis is an additional source, which accounts for up to $8 \%$ of new cases.[25] Data are collected from the medical records by specially trained registrars and are coded according to a nationally used manual. Information on patient characteristics, tumour characteristics, treatment, hospital of diagnosis, hospital of treatment and follow-up is recorded. For coding tumour site and morphology the International Classification of Diseases for Oncology (ICD-O) is used.[26] Cancers are staged according the TNM classification.[27] Quality of the data is high[28] and completeness is estimated to be at least 95\%.[29]

\section{Patients}

All patients with an invasive colon carcinoma, diagnosed in the period 2001-2006 were selected from the NCR. Diagnoses without histological confirmation, diagnoses based only on autopsy findings, patients living abroad and incomplete records were excluded from analyses. Tumour site was classified as ascendens (C18.0-C18.2), transversum and descendens (C18.3-C18.6), sigmoid (C18.7) and overlapping/unknown (C18.8-C18.9). Pathological stage was used to classify the extent of the disease. In cases where pathological stage was unknown, clinical stage was used.

\section{CCC-regions and hospitals}

The Netherlands are divided in 9 regions, each served by a Comprehensive Cancer Centre (CCC). Activities of CCCs are facilitation of consultancy services, development and implementation of guidelines, improving organisation of cancer care, coordinating palliative care and the population-based cancer registry. Each CCC serves an area covering five to twenty hospitals. All hospitals are affiliated to one centre. Within each CCCregion, treatment policies are discussed within multidisciplinary meetings which may lead to differences in oncologic care between the regions. Patients of all 97 hospitals in the Netherlands were included in the analyses.

A teaching hospital was defined as a hospital which provides medical training to residents. A distinction was made between a teaching hospital for surgery and a teaching hospital for internal medicine. All teaching hospitals for surgery were also teaching hospitals for internal medicine. University hospitals were teaching hospitals affiliated to a medical university. The one specialized oncology centre in the Netherlands was also classified as a university hospital.

Hospital volume was based on the mean number of diagnoses of colon carcinoma per year or on the mean number of colon resections for cancer per year. In the Netherlands, resections for colon cancer are in general performed in the hospital of diagnosis. Hospital volume was categorized into $<50,50-100$ and $>100$ diagnoses/resections per year.

For the analyses of treatment and relative survival, type of hospital was based on the hospital where the tumour was diagnosed reasoning that referral of patients for treatment in another hospital can also be 
considered as a good standard of care. For the analyses of postoperative mortality, type of hospital was based on the hospital where the surgery was performed.

\section{Statistical analyses}

Treatment was described as percentages per stage and age group ( $<75$ years and $\geq 75$ years).

\section{Variation in lymph node evaluation and adjuvant chemotherapy}

Logistic regression analysis was performed to examine the influence of age at diagnosis, gender, depth of invasion, nodal involvement, type of hospital of diagnosis, hospital volume, CCC-region and year of diagnosis on the odds of having an adequate lymph node evaluation (defined as $\geq 10$ or more evaluated lymph nodes). Patients whose tumour was removed by polypectomy and patients with distant metastasis (M1) were excluded from this analysis.

Moreover, the influence of age at diagnosis, gender, type of hospital of diagnosis, hospital volume, CCCregion and year of diagnosis on the odds of receiving adjuvant chemotherapy in patients with stage III disease colon cancer was analyzed using logistic regression analysis. To compare the performance of the individual hospitals for these two outcome measures, funnel plots were made using $95 \%$ control limits calculated around the mean of the $20 \%$ best performing hospitals. [30;31] The proportion of resections involving 10 or more evaluated lymph nodes was adjusted for age, gender, depth of invasion (pT) and nodal involvement $(\mathrm{pN})$. The proportion of resected patients receiving adjuvant chemotherapy was adjusted for age and gender. Each hospital was displayed as a scatter point presenting the adjusted rate for the outcome and the hospital volume.

\section{Variation in postoperative mortality}

Logistic regression analysis was used to investigate the odds of postoperative mortality by age at diagnosis, gender, depth of invasion, type of hospital of surgery, resection volume of hospital of surgery and CCCregion. Postoperative mortality was defined as death within 30 days after surgery. Patients with distant metastasis (M1) and acute surgery (date of surgery = date of first pathological examination) were excluded from this analysis. Postoperative mortality was analysed for tumours diagnosed in 2005 and 2006, because date of surgery was not registered in the NCR until 2005.

\section{Variation in survival}

Relative excess risks (RER) of dying according to hospital type and volume were estimated by means of multivariate relative survival analyses. Relative survival, an estimation of disease-specific survival, was calculated as the ratio of the observed rates in cancer patients to the expected rates in the general population using the Ederer method.[32] Results of the multivariate relative survival analyses were stratified by pathological stage of the tumour, because interaction was found between stage and hospital type. Length of follow-up was calculated as the time from diagnosis to death or to $1^{\text {st }}$ January 2008. Only first tumours were included in the multivariate relative survival analyses. 
STATA (version 10.0) was used for the analyses. A p-value below 0.05 was considered statistically significant. 
Results

In the period 2001-2006 39907 patients were newly diagnosed with colon carcinoma in the Netherlands, with an annual increase from 6016 in 2001 to 7360 in 2006. The male/female ratio was $1: 1$ and $40 \%$ of the patients was aged 75 years or older. Most frequent were stage II tumours (35\%). Stage was unknown for 3\% of the patients. Six percent of the patients were diagnosed in a university hospital and half of the patients were diagnosed in a hospital with 50 to 100 diagnoses per year (Table 1).

\section{Treatment}

Almost all patients with stages I-III disease underwent surgical resection. Around $10 \%$ of the stage I tumours were removed by endoscopic polypectomy. Of the patients younger than 75 years with stage III disease $76 \%$ received adjuvant chemotherapy. Among patients 75 years and older this proportion was $17 \%$. Around $60 \%$ of patients with stage IV disease underwent surgical resection of the primary tumour. The surgery of the primary tumour was combined with chemotherapy in 39\% of the patients younger than 75 years and in 10\% of the patients 75 years and older. The proportion of patients with stage IV who did not receive any treatment was $15 \%$ among patients younger than 75 years and $37 \%$ among patients 75 years and older (Figure 1).

\section{Lymph node evaluation}

The proportion of patients with 10 or more evaluated lymph nodes after resection increased from $31 \%$ in 2001 to $58 \%$ in 2006 , with an odds ratio of 3.29 (95\% Cl 3.00-3.60) in 2006 compared to 2001 . Female patients were more likely to have had 10 or more lymph nodes evaluated after resection. The odds ratio decreased with older age at diagnosis. The odds of having an adequate lymph node evaluation increased by year of diagnosis, up to 3.29 (95\% Cl 3.00-3.60) in 2006 compared to 2001. Patients with a larger depth of invasion and with nodal involvement were more likely to have had 10 or more lymph nodes evaluated. Patients diagnosed in a university hospital were more likely to have an adequate lymph node evaluation (OR 2.47; 95\% $\mathrm{Cl}$ 2.19-2.78). Patients diagnosed in a hospital with more than 100 resections per year were less likely to have an adequate lymph node evaluation (OR $0.70 ; 95 \% \mathrm{Cl} 0.64-0.77$ ). There was variation between CCC-regions in the odds of having 10 or more lymph nodes evaluated (Table 2). In the funnel plot, the adjusted proportion of patients with 10 or more evaluated lymph nodes is depicted for each hospital by mean number of colon resections per year, showing a large variation between the individual hospitals (Figure 2). The proportion of patients with an adequate lymph node evaluation ranged from more than $70 \%$ to less than $20 \%$ per hospital.

\section{Adjuvant chemotherapy}

In table 3 the odds of receiving adjuvant chemotherapy in patients with stage III tumours are shown. The use of adjuvant chemotherapy in patients with stage III tumours increased from 49\% in 2001 to $58 \%$ in 2006, with an odds ratio of 1.66 (95\% Cl 1.40-1.97) in 2006 compared to 2001. Female patients had a lower odds of receiving adjuvant chemotherapy (OR $0.88 ; 95 \% \mathrm{Cl} 0.80-0.98)$. The odds of receiving adjuvant chemotherapy decreased with increasing age, with an odds ratio of 0.03 (95\% $\mathrm{Cl} 0.03-0.04)$ in patients 75 years and older compared to those younger than 60 years. Patients diagnosed in a teaching hospital for 
internal medicine or in a university hospital had a lower odds of receiving adjuvant chemotherapy, compared to patients diagnosed in a non-teaching hospital. No significant difference in adjuvant chemotherapy administration between hospitals with different volumes was found. The administration of adjuvant chemotherapy differed between CCC-regions. However, there was also a wide variation between hospitals within the regions (data not shown). The funnel plot shows, for each hospital, the adjusted proportion of patients younger than 75 years with stage III disease receiving adjuvant chemotherapy by mean number of diagnosis per year, demonstrating some variation between the hospitals (Figure 3). The proportion of patients who received adjuvant chemotherapy varied from less than $50 \%$ to more than $90 \%$ for individual hospitals.

\section{Postoperative mortality}

Overall, $4.2 \%$ of the patients without distant metastasis at diagnosis undergoing an elective resection died within 30 days after surgery. Female patients had a lower odds of dying within 30 days after resection (OR $0.74 ; 95 \% \mathrm{Cl} 0.58-0.93$ ). The odds of dying within 30 days increased with increasing age, up to 11.61 (95\% $\mathrm{Cl} 6.13-21.98)$ for patients aged 75 years and older compared to those younger than 60 years. The odds was higher for T4-tumours compared with T1-T3 tumours (OR 1.87; 95\% Cl 1.37-2.56). No differences in postoperative mortality were found between hospital types, hospital volumes and CCC-regions (Table 4).

\section{Multivariate relative excess risks (RER) of dying}

In the multivariate model for all patients with colon cancer, patients diagnosed in a university hospital had a lower risk of dying compared to patients diagnosed in a non-teaching hospital (RER 0.76 ; 95\% $\mathrm{Cl} 0.69-0.83$ ). Patients diagnosed in hospitals with 50-100 diagnoses colon carcinoma per year and with more than 100 diagnoses colon carcinoma yearly had a lower risk of dying compared to patients diagnosed in a hospital with less than 50 diagnoses colon carcinoma yearly (RER $0.90 ; 95 \% \mathrm{Cl} 0.85-0.95$ and RER $0.86 ; 95 \% \mathrm{Cl}$ 0.80-0.93, respectively).

For stage I, survival was worse in patients diagnosed in a university hospital (RER 1.87; 95\% Cl 1.02-3.42). No differences in survival of patients with stage II disease were found between hospital types or between hospital volumes. Both among patients with stage III disease and among patients with stage IV disease, patients diagnosed in a university hospital had a lower risk of dying compared to patients diagnosed in a non-teaching hospital (RER 0.70; 95\% $\mathrm{Cl} 0.57-0.87$ and RER $0.77 ; 95 \% \mathrm{Cl} 0.69-0.86$, respectively). For stage IV, patients diagnosed in hospitals with 50-100 diagnoses colon carcinoma yearly and more than 100 diagnoses colon carcinoma yearly had a better survival (RER 0.88; 95\% $\mathrm{Cl} 0.82-0.95$ and RER $0.85 ; 95 \% \mathrm{Cl}$ 0.77-0.94, respectively) (Table 5). 
Discussion

In this nationwide population-based study, analyzing Netherlands Cancer Registry data of 39907 patients with colon carcinoma diagnosed in the period 2001-2006, considerable variation in treatment patterns and outcome was identified. The proportion of patients receiving optimal postoperative staging with adequate lymph node evaluation and accurate treatment for their cancer increased considerably over time, but differed widely between individual hospitals.

Being diagnosed in a hospital with a large patient volume or in a university hospital was positively related with the odds of having an adequate lymph node evaluation, and being diagnosed in a teaching hospital or in a university hospital had a negative relation with the odds of receiving adjuvant chemotherapy. Differences in relative survival were found between the various types and volumes of hospitals. In total, patients diagnosed in a university hospital or patients diagnosed in a hospital with a large volume had a better survival.

In literature, the number of studies evaluating differences in quality of care between various types of providers is overwhelming. Most studies show an inverse relationship between hospital volume and mortality, especially for high risk surgical procedures.[2;16;17] However, few studies have focused on other dimensions of quality of care besides differences in morbidity and mortality after surgery. In our study two important aspects of high leverage colon cancer treatment were investigated, lymph node evaluation and the administration of adjuvant chemotherapy. The choice for these specific process measures is supported by evidence from literature.[9;33]

\section{Lymph node evaluation}

Lymph node evaluation is crucial for staging and planning treatment in patients with colon cancer. Since adjuvant chemotherapy should be considered for patients with positive lymph nodes, inadequate lymph node examination might lead to understaging and undertreatment.[7;8] On the other hand, according to Dutch treatment guidelines, adjuvant chemotherapy should be considered for patients with stage II disease who had less than 10 evaluated lymph nodes, which could lead to overtreatment.[10] In our study we found that patients diagnosed in a university hospital were more likely to have more lymph nodes examined. This confirms the results of earlier studies from Canada and France.[34;35] The available resources in university hospitals to provide high quality multidisciplinary cancer care could be an explanation for this result. Other studies found a positive correlation between hospital volume and number of evaluated lymph nodes.[36;37] The current study, however, found an inverse relationship and showed that patients diagnosed in highvolume hospitals were less likely to have 10 or more lymph nodes examined. This suggests that an increased workload for pathology staff might lead to a less extensive lymph node evaluation, although a high-volume hospital not necessarily has to be served by a high-volume pathology laboratory. Furthermore, the workload per pathologist depends on the number of pathologists in a staff. Unfortunately, data on individual pathologists was not available in the NCR. However, the differences found between individual hospitals are remarkable.

\section{Adjuvant chemotherapy}


Ever since a randomized trial in the early nineties showed that patients with stage III colon carcinoma treated with adjuvant chemotherapy had a significant survival benefit[33], chemotherapy after surgery has been the standard of care for stage III patients with an adequate performance status.[10] However, not all patients with stage III disease receive adjuvant chemotherapy.[12] There are several explanations why elderly patients receive adjuvant chemotherapy less often than younger patients, such as the presence of comorbidities, unfavourable performance status or patient refusal.[38-40] Our study is hampered by the lack of information about comorbidities and performance status of the patient at time of diagnoses. Nevertheless marked differences in performance status of patients between hospitals in the Netherlands have not been reported.

University hospitals and teaching hospitals proved more restraint in the use of adjuvant chemotherapy compared to general hospitals. A French regional study showed the opposite: a lower relative risk for receiving adjuvant chemotherapy in patients treated in non-teaching hospitals compared to a single university centre.[34] An American study demonstrated that patients treated by surgeons practicing in a teaching hospital were more likely to see a medical oncologist.[41] Our contrasting findings suggest a more severe selection of patients for administering adjuvant chemotherapy in university hospitals.

\section{Postoperative mortality}

In our study, age was an important predictor for postoperative mortality. According to a review of the Colorectal Cancer Collaborative Group, the increased proportion of elderly patients undergoing emergency surgery, together with multiple co morbidities, could contribute to this increased risk of postoperative mortality.[42] However, in our study only elective procedures were included, with a very high risk of postoperative mortality in the elderly patient group compared to the younger patient group. Elderly patients undergoing major surgery can have similar outcomes as younger patients if carefully selected.[42;43] However, the risk of obstruction or even perforation in colon cancer patients forces surgeons to perform surgery in elderly patients with an unfavourable physical status. Apparently, colon resections in elderly people are high risk procedures, in which specific experience and expertise is needed.

Nevertheless, no association between postoperative mortality and the volume or teaching status of hospitals was found in our study. This confirms the results of earlier Dutch and Canadian studies, in which no association between type or volume of hospitals and postoperative mortality was found.[18;44] For other high-risk operations, like pancreatic or esophageal resections, clear differences between low- and highvolume hospitals were demonstrated, also in the Netherlands.[2;3;45] Due to the high incidence of colon carcinoma, hospital volumes are substantially higher than the hospital volume of, for example, pancreas or esophageal cancer, which might explain our results. Nevertheless, despite the lack of an inverse relationship between hospital volume and postoperative mortality, our study identified important differences in quality of care between hospitals in the Netherlands, as shown above.

\section{Survival}

Some consider survival as the most important performance indicator for cancer treatments. Process measures, like the number of lymph nodes evaluated and the use of adjuvant chemotherapy investigated in the current study, are futile, when a relationship with direct outcome measures, like survival, is lacking. 
Survival was analyzed in the present study and significant differences between hospital types and volumes were found. Survival of patients diagnosed in university hospitals was better than in other hospitals, especially those with a high volume of colon cancer diagnoses. This finding does not parallel the restrained use of adjuvant chemotherapy in stage III patients diagnosed in these university hospitals, although it could be related to a better patient selection for adjuvant chemotherapy. Furthermore, one might speculate about a more aggressive and multidisciplinary approach in case of recurrence. Unfortunately, information on incidence and treatment of recurrences is lacking in the Netherlands Cancer Registry. The relatively low survival of patients diagnosed in low volume hospitals was reported before by a nested cohort study form the US.[46] Another American population-based study found an association between both surgeon and hospital volume and outcome, but hospital volume had a stronger effect.[47]

Comparing quality of care between hospitals on the basis of structural characteristics like volume and teaching status might have important disadvantages. Investigating acknowledged measures of quality of care, our study shows that variation was largest on the level of the individual hospital. Characterisations of hospitals by, for instance, volume, do not necessarily correspond with quality of care and do not reveal the differences in patterns of care that lead to poor or better outcomes. The advantage of direct measurement of the care process and its outcome, is the possibility to feed this information back to individual hospitals. Several studies have stressed the beneficial effects of quality assurance and outcome analysis in the evaluation of the quality of cancer care.

In conclusion, we found variation in treatment and outcome of patients diagnosed with colon cancer in the Netherlands, with differences based on hospital types and volumes. However, variation in quality of care seemed mainly determined on the level of the individual hospital. 
Acknowledgements

The authors would like to thank the Netherlands Cancer Registry for providing data. 
Conflict of interest statement

None declared. 
Table 1: Description of study population ( $\mathrm{N}=39907)$

\begin{tabular}{|c|c|c|}
\hline & $\mathrm{N}$ & $\%$ \\
\hline \multicolumn{3}{|l|}{ Gender } \\
\hline Male & 19882 & 49.8 \\
\hline Female & 20025 & 50.2 \\
\hline \multicolumn{3}{|l|}{ Age at diagnosis } \\
\hline$<60$ & 7269 & 18.2 \\
\hline $60-74$ & 16553 & 41.5 \\
\hline $75+$ & 16085 & 40.3 \\
\hline \multicolumn{3}{|l|}{ Year of diagnosis } \\
\hline 2001 & 6016 & 15.1 \\
\hline 2002 & 6127 & 15.4 \\
\hline 2003 & 6487 & 16.3 \\
\hline 2004 & 6840 & 17.1 \\
\hline 2005 & 7077 & 17.7 \\
\hline 2006 & 7360 & 18.4 \\
\hline \multicolumn{3}{|l|}{ Tumour location } \\
\hline Ascendens & 14434 & 36.2 \\
\hline Transversum and descendens & 9318 & 23.4 \\
\hline Sigmoid & 15091 & 37.8 \\
\hline Overlapping/Unknown & 1064 & 2.7 \\
\hline \multicolumn{3}{|l|}{ Pathological stage } \\
\hline I & 6209 & 15.6 \\
\hline II & 13812 & 34.6 \\
\hline III & 10024 & 25.1 \\
\hline IV & 8662 & 21.7 \\
\hline unknown & 1200 & 3.0 \\
\hline \multicolumn{3}{|l|}{ Teaching hospital surgery } \\
\hline No & 16808 & 42.1 \\
\hline Yes & 20651 & 51.8 \\
\hline University hospital & 2448 & 6.1 \\
\hline \multicolumn{3}{|l|}{ Teaching hospital internal medicine } \\
\hline No & 12231 & 30.7 \\
\hline Yes & 25228 & 63.2 \\
\hline University hospital & 2448 & 6.1 \\
\hline \multicolumn{3}{|l|}{ Annual volume of hospital of diagnosis } \\
\hline$<50$ diagnoses colon carcinoma & 7484 & 18.8 \\
\hline 50-100 diagnoses colon carcinoma & 19816 & 49.7 \\
\hline$>100$ diagnoses colon carcinoma & 12607 & 31.6 \\
\hline Comprehensive Cancer Centre regio & & \\
\hline
\end{tabular}




\begin{tabular}{lcc}
\hline 1 & 6900 & 17.3 \\
2 & 5496 & 13.8 \\
3 & 3529 & 8.8 \\
4 & 2930 & 7.3 \\
5 & 4044 & 10.1 \\
6 & 5632 & 14.1 \\
7 & 5651 & 14.2 \\
8 & 2485 & 6.2 \\
9 & 3240 & 8.1 \\
\hline
\end{tabular}


Table 2: Odds ratio of having 10 or more lymph nodes evaluated in patients with stage I-III (multivariate logistic regression analysis)

\begin{tabular}{|c|c|c|}
\hline & OR & $95 \% \mathrm{Cl}$ \\
\hline \multicolumn{3}{|l|}{ Gender } \\
\hline Male & 1.00 & Reference \\
\hline Female & $1.14^{*}$ & $1.08-1.20$ \\
\hline \multicolumn{3}{|l|}{ Age at diagnosis } \\
\hline$<60$ years & 1.00 & Reference \\
\hline $60-74$ years & $0.74^{*}$ & $0.69-0.79$ \\
\hline$\geq 75$ years & $0.54^{*}$ & $0.50-0.58$ \\
\hline \multicolumn{3}{|l|}{ Year of diagnosis } \\
\hline 2001 & 1.00 & Reference \\
\hline 2002 & $1.16^{*}$ & $1.06-1.28$ \\
\hline 2003 & $1.30^{*}$ & $1.18-1.43$ \\
\hline 2004 & $1.61^{*}$ & $1.47-1.77$ \\
\hline 2005 & $2.57^{*}$ & $2.34-2.81$ \\
\hline 2006 & $3.29^{*}$ & $3.00-3.60$ \\
\hline \multicolumn{3}{|l|}{ Depth of invasion } \\
\hline pT1 & 1.00 & Reference \\
\hline рT2 & $3.06^{*}$ & $2.64-3.55$ \\
\hline рT3 & $5.02^{*}$ & $4.38-5.76$ \\
\hline pT4 & $4.62^{*}$ & $3.97-5.38$ \\
\hline \multicolumn{3}{|l|}{ Nodal involvement } \\
\hline pNO & 1.00 & Reference \\
\hline $\mathrm{pN}+$ & $1.27^{\star}$ & $1.20-1.34$ \\
\hline \multicolumn{3}{|l|}{ Hospital of diagnosis } \\
\hline Non-teaching hospital & 1.00 & Reference \\
\hline Teaching hospital for surgery & 1.04 & $0.97-1.11$ \\
\hline University hospital & $2.47^{\star}$ & $2.19-2.78$ \\
\hline \multicolumn{3}{|l|}{ Annual volume of hospital of diagnosis } \\
\hline$<50$ resections colon carcinoma & 1.00 & Reference \\
\hline 50-100 resections colon carcinoma & 0.97 & $0.91-1.04$ \\
\hline$>100$ resections colon carcinoma & $0.70^{*}$ & $0.64-0.77$ \\
\hline \multicolumn{3}{|l|}{ Comprehensive Cancer Centre region } \\
\hline 1 & 1.00 & Reference \\
\hline 2 & $1.22^{*}$ & $1.11-1.34$ \\
\hline 3 & $1.32^{*}$ & $1.19-1.47$ \\
\hline 4 & $1.38^{\star}$ & $1.24-1.55$ \\
\hline 5 & $1.19^{*}$ & 1.08-1.32 \\
\hline 6 & 0.92 & $0.84-1.01$ \\
\hline
\end{tabular}




\begin{tabular}{lll}
\hline 7 & $0.70^{*}$ & $0.64-0.78$ \\
8 & $0.85^{*}$ & $0.75-0.97$ \\
9 & $1.28^{*}$ & $1.15-1.42$ \\
\hline${ }^{*} \mathrm{p}<0.05$ &
\end{tabular}


Table 3: Odds ratio of receiving adjuvant chemotherapy in patients with stage III disease (multivariate logistic regression analysis)

\begin{tabular}{|c|c|c|}
\hline & OR & $95 \% \mathrm{Cl}$ \\
\hline \multicolumn{3}{|l|}{ Gender } \\
\hline Male & 1.00 & Reference \\
\hline Female & $0.88^{*}$ & $0.80-0.98$ \\
\hline \multicolumn{3}{|l|}{ Age at diagnosis } \\
\hline$<60$ years & 1.00 & Reference \\
\hline $60-74$ years & $0.40^{*}$ & $0.34-0.46$ \\
\hline$\geq 75$ years & $0.03^{*}$ & $0.03-0.04$ \\
\hline \multicolumn{3}{|l|}{ Year of diagnosis } \\
\hline 2001 & 1.00 & Reference \\
\hline 2002 & 1.05 & $0.88-1.25$ \\
\hline 2003 & $1.22^{*}$ & $1.02-1.46$ \\
\hline 2004 & $1.34^{*}$ & $1.13-1.59$ \\
\hline 2005 & $1.44^{*}$ & $1.21-1.71$ \\
\hline 2006 & $1.66^{*}$ & $1.40-1.97$ \\
\hline \multicolumn{3}{|l|}{ Hospital of diagnosis } \\
\hline Non-teaching hospital & 1.00 & Reference \\
\hline Teaching hospital for internal medicine & $0.85^{*}$ & $0.73-0.98$ \\
\hline University hospital & $0.56^{*}$ & $0.45-0.70$ \\
\hline \multicolumn{3}{|l|}{ Annual volume of hospital of diagnosis } \\
\hline$<50$ diagnoses colon carcinoma & 1.00 & Reference \\
\hline 50-100 diagnoses colon carcinoma & 1.04 & $0.89-1.22$ \\
\hline >100 diagnoses colon carcinoma & 0.91 & $0.74-1.11$ \\
\hline \multicolumn{3}{|l|}{ Comprehensive Cancer Centre region } \\
\hline 1 & 1.00 & Reference \\
\hline 2 & 0.84 & $0.70-1.02$ \\
\hline 3 & $0.73^{*}$ & $0.59-0.90$ \\
\hline 4 & 0.86 & $0.69-1.07$ \\
\hline 5 & $0.76^{*}$ & $0.63-0.93$ \\
\hline 6 & 0.98 & $0.82-1.18$ \\
\hline 7 & 0.88 & $0.73-1.06$ \\
\hline 8 & $1.66^{*}$ & $1.29-2.12$ \\
\hline 9 & 0.84 & $0.68-1.05$ \\
\hline
\end{tabular}

${ }^{*} p<0.05$ 
Table 4: Odds ratio of death within 30 days after resection in patients without distant metastasis (multivariate logistic regression analysis)

\begin{tabular}{|c|c|c|}
\hline & OR & $95 \% \mathrm{Cl}$ \\
\hline \multicolumn{3}{|l|}{ Gender } \\
\hline Male & 1.00 & Reference \\
\hline Female & $0.74^{*}$ & $0.58-0.93$ \\
\hline \multicolumn{3}{|l|}{ Age at diagnosis } \\
\hline$<60$ years & 1.00 & Reference \\
\hline $60-74$ years & $2.55^{\star}$ & $1.30-5.00$ \\
\hline$\geq 75$ years & $11.61^{*}$ & $6.13-21.98$ \\
\hline \multicolumn{3}{|l|}{ Depth of invasion } \\
\hline T1-T2-T3 & 1.00 & Reference \\
\hline T4 & $1.87^{*}$ & $1.37-2.56$ \\
\hline Unknown & 1.58 & $0.37-6.81$ \\
\hline \multicolumn{3}{|l|}{ Hospital of surgery } \\
\hline Non-teaching hospital & 1.00 & Reference \\
\hline Teaching hospital for surgery & 0.95 & $0.71-1.28$ \\
\hline University hospital & 1.06 & $0.63-1.80$ \\
\hline \multicolumn{3}{|l|}{ Annual volume of hospital of surgery } \\
\hline$<50$ resections colon carcinoma & 1.00 & Reference \\
\hline 50-100 resections colon carcinoma & 1.33 & $0.93-1.88$ \\
\hline$>100$ resections colon carcinoma & 1.23 & $0.77-1.98$ \\
\hline \multicolumn{3}{|l|}{ Comprehensive Cancer Centre region } \\
\hline 1 & 1.00 & Reference \\
\hline 2 & 0.69 & $0.44-1.08$ \\
\hline 3 & 0.84 & $0.51-1.38$ \\
\hline 4 & 0.95 & $0.58-1.57$ \\
\hline 5 & 0.95 & $0.61-1.47$ \\
\hline 6 & 0.83 & $0.54-1.27$ \\
\hline 7 & 1.07 & $0.71-1.63$ \\
\hline 8 & 0.61 & $0.32-1.16$ \\
\hline 9 & 0.83 & $0.50-1.38$ \\
\hline
\end{tabular}

${ }^{*} p<0.05$ 
Table 5: Relative excess risks (RER) of dying for patients with colon cancer diagnosed in the period 2001-2006, according to stage (multivariate relative survival analysis)

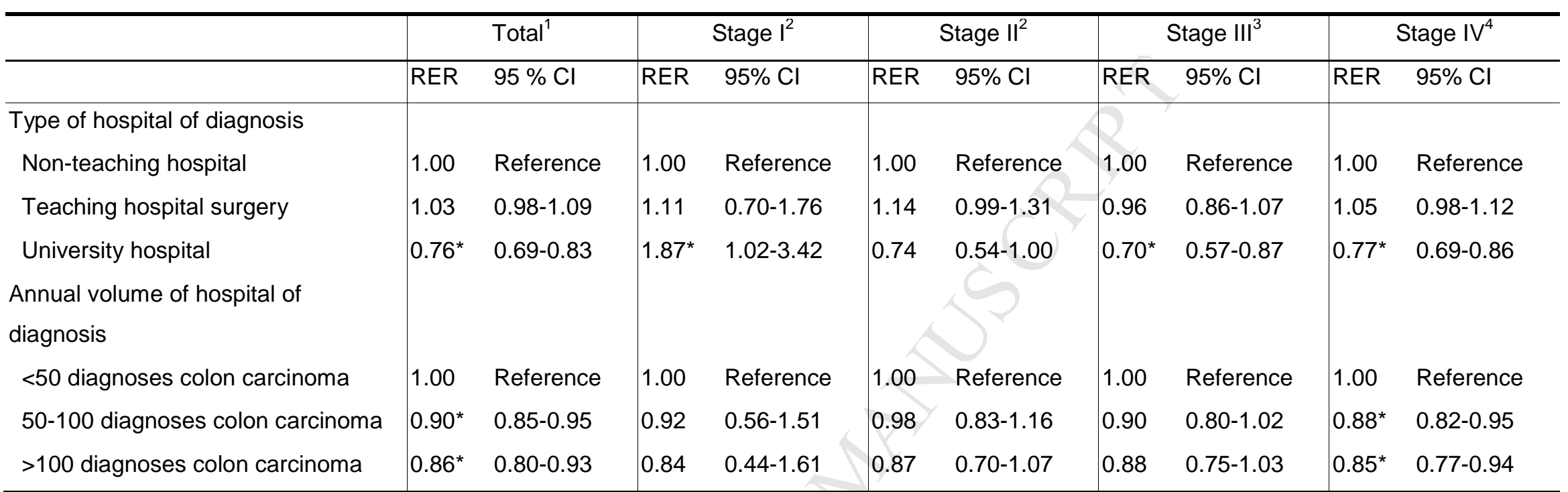

${ }^{1}$ Adjusted for gender, age at diagnosis, grade, year of diagnosis, tumour location, stage, surgery, chemotherapy and CCC-region

${ }^{2}$ Adjusted for gender, age at diagnosis, grade, year of diagnosis, tumour location, depth of invasion, surgery and CCC-region

${ }^{3}$ Adjusted for gender, age at diagnosis, grade, year of diagnosis, tumour location, depth of invasion, surgery, chemotherapy, number of positive nodes and CCC-region

${ }^{4}$ Adjusted for gender, age at diagnosis, grade, year of diagnosis, tumour location, depth of invasion, surgery, chemotherapy and CCC-region

${ }^{*} p<0.05$ 
Figure 1: Treatment according to stage and age at diagnosis

Figure 2: Funnel plot of proportion of patients of whom 10 or more lymph nodes were evaluated after resection in the period 2001-2006 according to mean number of colon resections per year

Figure 3: Funnel plot of proportion of patients receiving adjuvant chemotherapy in patients $<75$ years with stage III disease receiving adjuvant chemotherapy in the period 2001-2006 according to mean number of diagnosis per year 
Reference List

[1] Hewitt, M. and Simone, J. Ensuring Quality Cancer Care. Washington DC: National Academy Press; 1999.

[2] Birkmeyer JD, Siewers AE, Finlayson EV, Stukel TA, Lucas FL, Batista I, Welch HG, Wennberg DE. Hospital Volume and Surgical Mortality in the United States. N Engl J Med 2002; 346(15): 1128-37.

[3] Birkmeyer JD, Stukel TA, Siewers AE, Goodney PP, Wennberg DE, Lucas FL. Surgeon Volume and Operative Mortality in the United States. N Engl J Med 2003; 349(22): 2117-27.

[4] Chowdhury MM, Dagash H, Pierro A. A Systematic Review of the Impact of Volume of Surgery and Specialization on Patient Outcome. Br J Surg 2007; 94(2): 145-61.

[5] Comprehensive Cancer Centres. http://www.cancerregistry.nl Accessed on: 18-5-2009.

[6] Statistics Netherlands. http://statline.cbs.nl/StatWeb Accessed on: 3-5-2009.

[7] Benson AB, III, Schrag D, Somerfield MR, Cohen AM, Figueredo AT, Flynn PJ, Krzyzanowska MK, Maroun J, McAllister P, Van CE, Brouwers M, Charette M, Haller DG. American Society of Clinical Oncology Recommendations on Adjuvant Chemotherapy for Stage II Colon Cancer. J Clin Oncol 2004; 22(16): 3408-19.

[8] Berger AC, Sigurdson ER, LeVoyer T, Hanlon A, Mayer RJ, MacDonald JS, Catalano PJ, Haller DG. Colon Cancer Survival Is Associated With Decreasing Ratio of Metastatic to Examined Lymph Nodes. J Clin Oncol 2005; 23(34): 8706-12.

[9] Johnson PM, Porter GA, Ricciardi R, Baxter NN. Increasing Negative Lymph Node Count Is Independently Associated With Improved Long-Term Survival in Stage IIIB and IIIC Colon Cancer. J Clin Oncol 2006; 24(22): 3570-5.

[10] National Working Group on Gastrointestinal Cancers. Guideline colon cancer: http://www.oncoline.nl Accessed on: 16-10-2009.

[11] Lemmens VE, van L, I, Janssen-Heijnen ML, Rutten HJ, Verheij CD, Coebergh JW. Pathology Practice Patterns Affect Lymph Node Evaluation and Outcome of Colon Cancer: a Population-Based Study. ANN ONCOL 2006; 17(12): 1803-9.

[12] Van Steenbergen LN, Rutten HJ, Creemers GJ, Pruijt JF, Coebergh JW, Lemmens VE. Large Age and Hospital-Dependent Variation in Administration of Adjuvant Chemotherapy for Stage III Colon Cancer in Southern Netherlands. ANN ONCOL 2009.

[13] Chaudhry R, Goel V, Sawka C. Breast Cancer Survival by Teaching Status of the Initial Treating Hospital. CMAJ 2001; 164(2): 183-8.

[14] Cheung MC, Hamilton K, Sherman R, Byrne MM, Nguyen DM, Franceschi D, Koniaris LG. Impact of Teaching Facility Status and High-Volume Centers on Outcomes for Lung Cancer Resection: an Examination of 13,469 Surgical Patients. Ann Surg Oncol 2009; 16(1): 3-13.

[15] Holm T, Johansson H, Cedermark B, Ekelund G, Rutqvist LE. Influence of Hospital- and SurgeonRelated Factors on Outcome After Treatment of Rectal Cancer With or Without Preoperative Radiotherapy. Br J Surg 1997; 84(5): 657-63.

[16] Begg CB, Cramer LD, Hoskins WJ, Brennan MF. Impact of Hospital Volume on Operative Mortality for Major Cancer Surgery. JAMA 1998; 280(20): 1747-51.

[17] Halm EA, Lee C, Chassin MR. Is Volume Related to Outcome in Health Care? A Systematic Review and Methodologic Critique of the Literature. Ann Intern Med 2002; 137(6): 511-20. 
[18] Simunovic M, Rempel E, Theriault ME, Coates A, Whelan T, Holowaty E, Langer B, Levine M. Influence of Hospital Characteristics on Operative Death and Survival of Patients After Major Cancer Surgery in Ontario. Can J Surg 2006; 49(4): 251-8.

[19] Parry JM, Collins S, Mathers J, Scott NA, Woodman CB. Influence of Volume of Work on the Outcome of Treatment for Patients With Colorectal Cancer. Br J Surg 1999; 86(4): 475-81.

[20] Harmon JW, Tang DG, Gordon TA, Bowman HM, Choti MA, Kaufman HS, Bender JS, Duncan MD, Magnuson TH, Lillemoe KD, Cameron JL. Hospital Volume Can Serve As a Surrogate for Surgeon Volume for Achieving Excellent Outcomes in Colorectal Resection. Ann Surg 1999; 230(3): 404-11.

[21] Hannan EL, Radzyner M, Rubin D, Dougherty J, Brennan MF. The Influence of Hospital and Surgeon Volume on in-Hospital Mortality for Colectomy, Gastrectomy, and Lung Lobectomy in Patients With Cancer. Surgery 2002; 131(1): 6-15.

[22] Finlayson EV, Goodney PP, Birkmeyer JD. Hospital Volume and Operative Mortality in Cancer Surgery: a National Study. Arch Surg 2003; 138(7): 721-5.

[23] Dimick JB, Cowan JA, Jr., Upchurch GR, Jr., Colletti LM. Hospital Volume and Surgical Outcomes for Elderly Patients With Colorectal Cancer in the United States. J Surg Res 2003; 114(1): 50-6.

[24] Blomqvist P, Ekbom A, Nyren O, Krusemo U, Bergstrom R, Adami HO. Survival After Colon Cancer 1973-1990 in Sweden. Convergence Between Catchment Areas. Ann Surg 1997; 225(2): 208-16.

[25] Visser O, Coebergh JWW, Van Dijck J.A.A.M., Siesling S. Incidence of cancer in the Netherlands 1998.Utrecht: Vereniging van Integrale Kankercentra, 2002.

[26] Fritz A, Percy C, Jack A, Shanmugaratnam K, Sobin L, Parkin DM, Whelan S, (eds). International Classification of Diseases for Oncology. Third edition. Geneva: WHO, 2000.

[27] Wittekind C, Greene FL, Hutter RVP, Klimpfinger M, Sobin LH, (eds). TNM Atlas. Berlin: SpringerVerlag, 2004.

[28] Schouten LJ, Jager JJ, van den Brandt PA. Quality of Cancer Registry Data: a Comparison of Data Provided by Clinicians With Those of Registration Personnel. Br J Cancer 1993; 68(5): 974-7.

[29] Schouten LJ, Hoppener P, van den Brandt PA, Knottnerus JA, Jager JJ. Completeness of Cancer Registration in Limburg, The Netherlands. Int J Epidemiol 1993; 22(3): 369-76.

[30] Agresti A, Coul BA. Approximate Is Better Than "Exact" for Interval Estimation of Binomial Proportions. the American Statistician 1998; 52(2): 119-26.

[31] Spiegelhalter DJ. Funnel Plots for Comparing Institutional Performance. Stat Med 2005; 24(8): 1185202.

[32] Ederer F, Heise H. Instructions to IBM 650 Programmers in Processing Survival Computations. Bethesda MD: National Cancer Institute, 1959.

[33] Moertel CG, Fleming TR, MacDonald JS, Haller DG, Laurie JA, Tangen CM, Ungerleider JS, Emerson WA, Tormey DC, Glick JH, Veeder MH, Mailliard JA. Fluorouracil Plus Levamisole As Effective Adjuvant Therapy After Resection of Stage III Colon Carcinoma: a Final Report. Ann Intern Med 1995; 122(5): 321-6.

[34] Bouhier K, Maurel J, Lefevre H, Bouin M, Arsene D, Launoy G. Changing Practices for Diagnosis and Treatment of Colorectal Cancer in Calvados: 1990-1999. Gastroenterol Clin Biol 2004; 28(4): 371-6.

[35] Wright FC, Law CH, Last L, Khalifa M, Arnaout A, Naseer Z, Klar N, Gallinger S, Smith AJ. Lymph Node Retrieval and Assessment in Stage II Colorectal Cancer: a Population-Based Study. Ann Surg Oncol 2003; 10(8): 903-9. 
[36] Bilimoria KY, Palis B, Stewart AK, Bentrem DJ, Freel AC, Sigurdson ER, Talamonti MS, Ko CY. Impact of Tumor Location on Nodal Evaluation for Colon Cancer. Dis Colon Rectum 2008; 51(2): 154-61.

[37] Miller EA, Woosley J, Martin CF, Sandler RS. Hospital-to-Hospital Variation in Lymph Node Detection After Colorectal Resection. Cancer 2004; 101(5): 1065-71.

[38] Ayanian JZ, Zaslavsky AM, Fuchs CS, Guadagnoli E, Creech CM, Cress RD, O'Connor LC, West DW, Allen ME, Wolf RE, Wright WE. Use of Adjuvant Chemotherapy and Radiation Therapy for Colorectal Cancer in a Population-Based Cohort. J Clin Oncol 2003; 21(7): 1293-300.

[39] Kohne CH, Grothey A, Bokemeyer C, Bontke N, Aapro M. Chemotherapy in Elderly Patients With Colorectal Cancer. ANN ONCOL 2001; 12(4): 435-42.

[40] Lemmens VE, van Halteren AH, Janssen-Heijnen ML, Vreugdenhil G, Repelaer van Driel OJ, Coebergh JW. Adjuvant Treatment for Elderly Patients With Stage III Colon Cancer in the Southern Netherlands Is Affected by Socioeconomic Status, Gender, and Comorbidity. ANN ONCOL 2005; 16(5): 767-72.

[41] Luo R, Giordano SH, Zhang DD, Freeman J, Goodwin JS. The Role of the Surgeon in Whether Patients With Lymph Node-Positive Colon Cancer See a Medical Oncologist. Cancer 2007; 109(5): 975-82.

[42] Surgery for Colorectal Cancer in Elderly Patients: a Systematic Review. Colorectal Cancer Collaborative Group. Lancet 2000; 356(9234): 968-74.

[43] Koruda MJ, Sheldon GF. Surgery in the Aged. Adv Surg 1991; 24: 293-331.

[44] Engel AF, Oomen JL, Knol DL, Cuesta MA. Operative Mortality After Colorectal Resection in the Netherlands. Br J Surg 2005; 92(12): 1526-32.

[45] Wouters MW, Wijnhoven BP, Karim-Kos HE, Blaauwgeers HG, Stassen LP, Steup WH, Tilanus HW, Tollenaar RA. High-Volume Versus Low-Volume for Esophageal Resections for Cancer: the Essential Role of Case-Mix Adjustments Based on Clinical Data. Ann Surg Oncol 2008; 15(1): 80-7.

[46] Meyerhardt JA, Catalano PJ, Schrag D, Ayanian JZ, Haller DG, Mayer RJ, MacDonald JS, Benson AB, III, Fuchs CS. Association of Hospital Procedure Volume and Outcomes in Patients With Colon Cancer at High Risk for Recurrence. Ann Intern Med 2003; 139(8): 649-57.

[47] Schrag D, Panageas KS, Riedel E, Hsieh L, Bach PB, Guillem JG, Begg CB. Surgeon Volume Compared to Hospital Volume As a Predictor of Outcome Following Primary Colon Cancer Resection. J Surg Oncol 2003; 83(2): 68-78. 


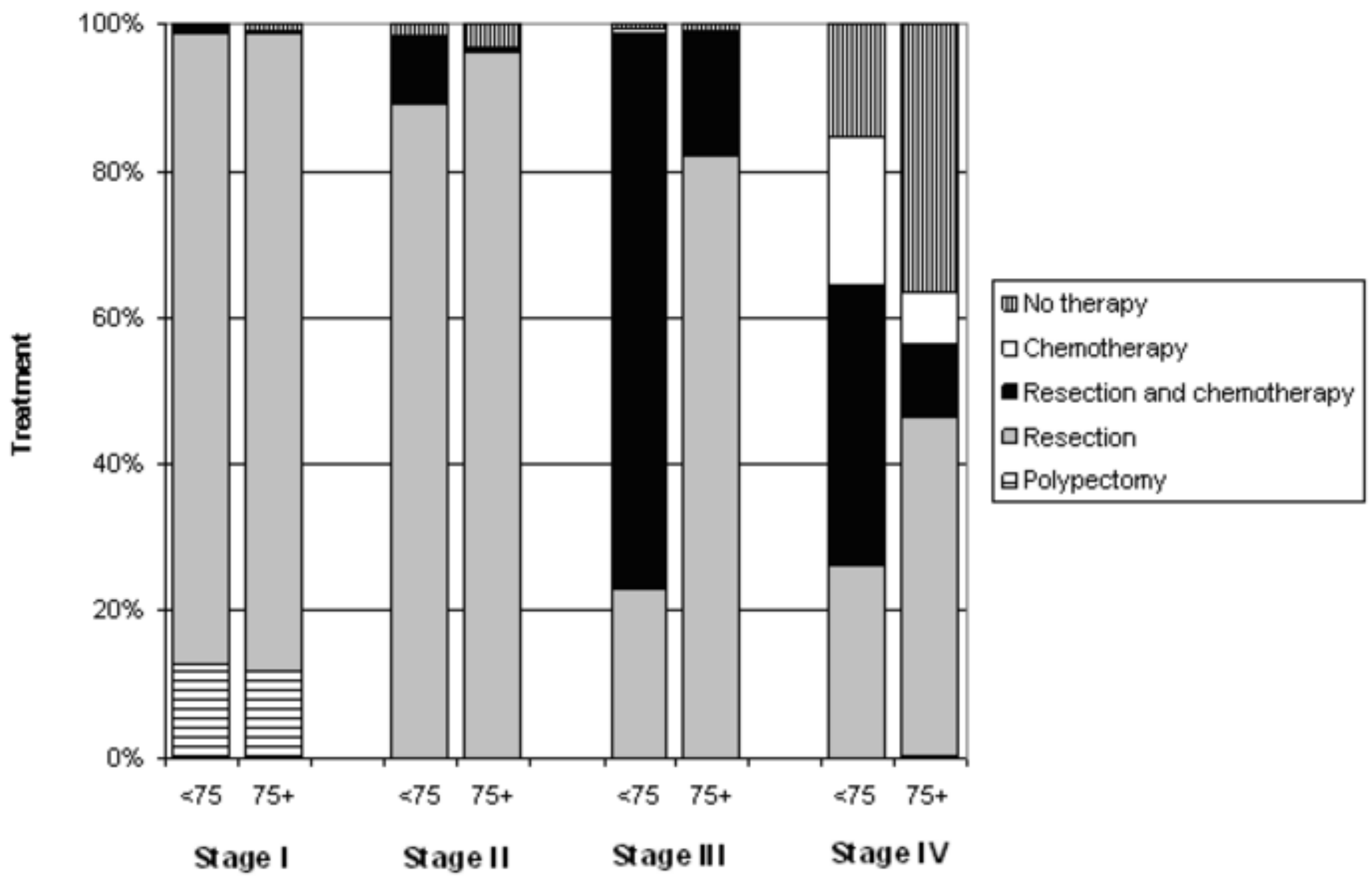




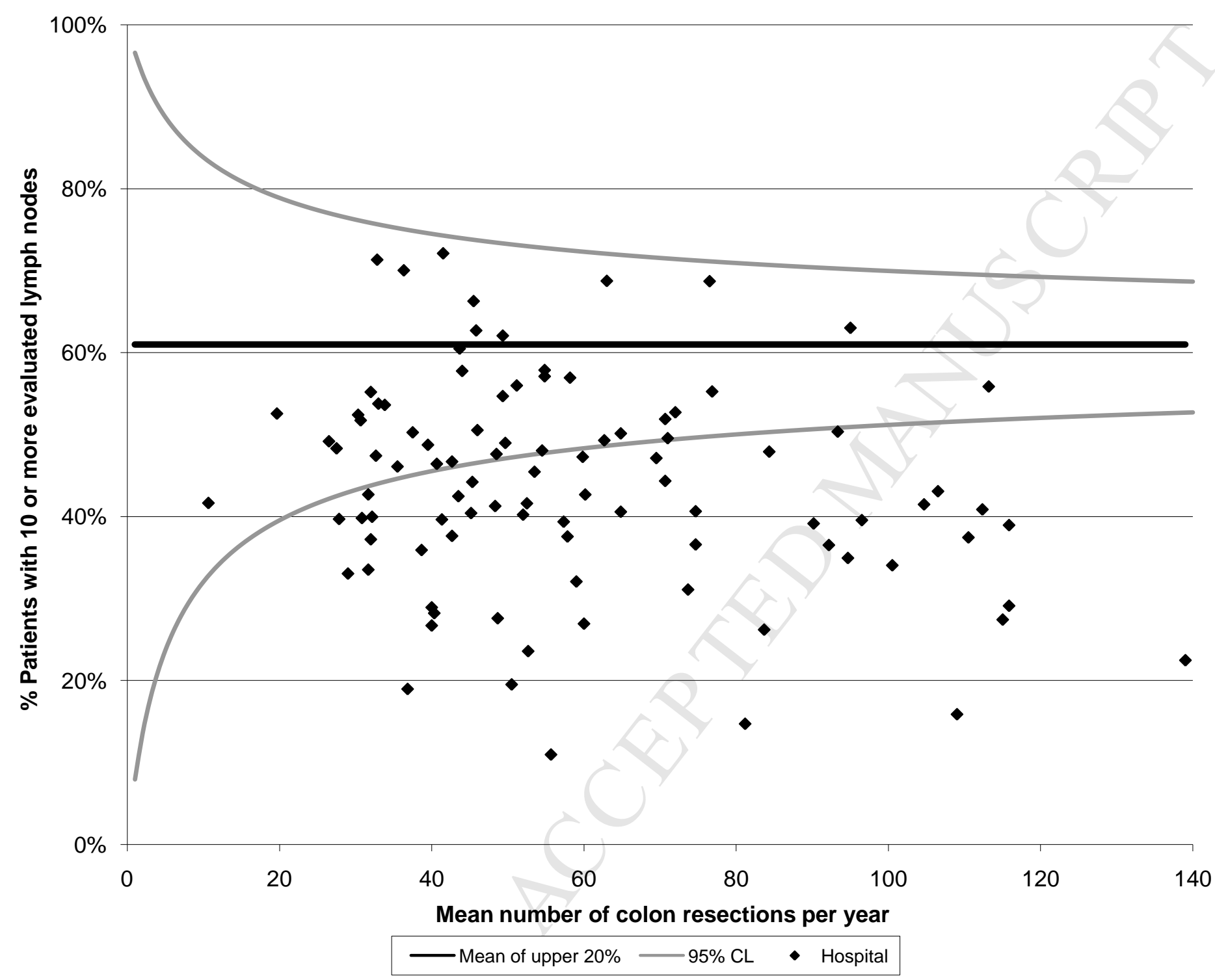




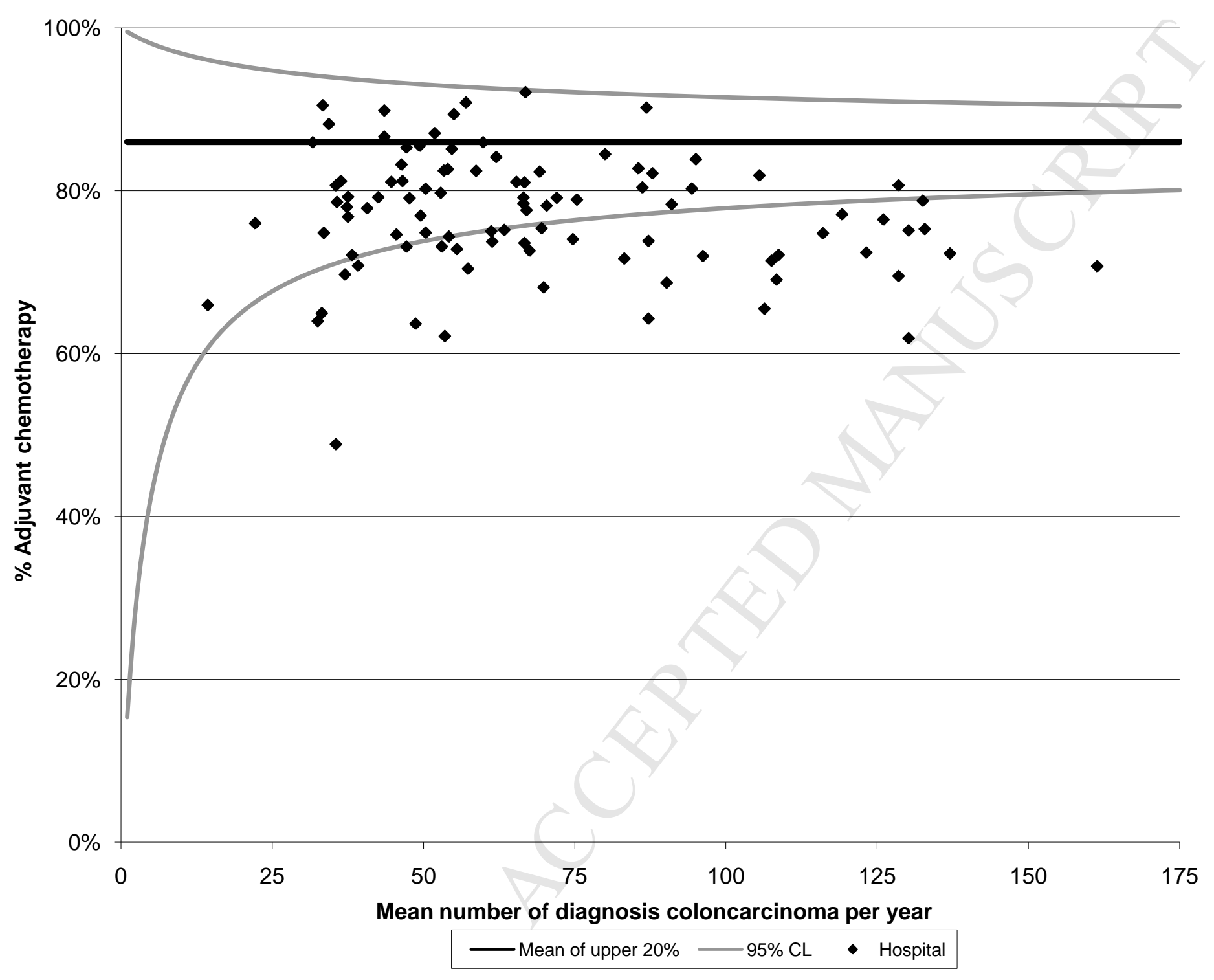

